\title{
Main Points in Opening Address by German Federal Minister of the Environment, Nature Protection, and Nuclear Safety
}

\author{
Additional Greenhouse Effect and Energy Use
}

The threat of climate change from the additional, anthropogenic 'greenhouse' effect poses a danger of global proportions. If no countermeasures are taken, the consequences may well be dramatic: Everybody world-wide will be the loser, with nobody a winner. This is also the conclusion reached by the Intergovernmental Panel on Climate Change (IPCC), the Second World Climate Conference (held [in this very hall in the] autumn of 1990), and the Enquiry (Enquête) Commission on Preventive Action to Protect the Earth's Atmosphere (which was set up by the German Bundestag).

Of course [it can be said that] we need even more scientific proof and work, but the evidence tells us that it is time to act now! The need for more research cannot be misused as an alibi for inaction. We know that the following areas are at the root of the additional, anthropogenic 'greenhouse' effect (the proportions given are for global levels):

- energy: around 50\%;

- chemical products, primarily chlorofluorocarbons (CFCs): around 20\%;

- destruction of woodlands, in particular of the tropical forests: around $15 \%$; and

- agriculture and other areas (waste-deposit sites, etc.): around $15 \%$.

A Clean Energy Conference and a [Global] Energy Charter are [consequently] of the highest importance. Energy-use does not only pose a danger to our climate. It is also the cause of other types of environmental damage, such as, for example, acidification of soil and flowing waters, and damage to forests. Measures to put a check on the 'greenhouse' effect must be taken in such a way that they also reduce the other forms of environmental damage caused by energy consumption. What is required, therefore, is to find [and practise all] possible ways of minimizing or limiting the negative consequences that energy-use has for Mankind and the environment, while at the same time protecting also the limited resources of our blue planet Earth. These are 'no-regret-measures'!

Just under $90 \%$ of the world's total commercial primary energy-use comes from fossil fuels. Around 50\% of the global emissions of carbon dioxide $\left(\mathrm{CO}_{2}\right)$, methane $\left(\mathrm{CH}_{4}\right)$, nitrogen oxides $\left(\mathrm{NO}_{\mathrm{x}}\right)$, carbon monoxide (CO), and volatile organic compounds (VOCs), come from the energy sector and contribute to the additional, anthropogenic 'greenhouse' effect. Around $40 \%$ comes from $\mathrm{CO}_{2}$ emissions, with the other energy-related emissions totalling around $10 \%$.

If emissions of climate-relevant gases continue until the year 2100 to rise at the same rate as they do today, then the average global temperature will rise by between 3 and $5^{\circ} \mathrm{C}$ (most probably by $5^{\circ} \mathrm{C}$ ) over their preindustrial levels. This means that, within the space of just 100 years, the rise in temperature which took place in the 18,000 years from the [Pleistocene] Ice-Age to the present day will be equalled.

\section{Consequences of Climatic Change}

It is particularly the [less-developed] countries that will be hit by the consequences of climate change and particularly the industrialized countries which are responsible for this development [as some] $80 \%$ of the energy consumption is by $20 \%$ of world-wide population [the damages being proportional]. Until now there is by no means a sustainable life-style in the industrialized world. This will have the effect of creating additional conflicts in future North-South relations. At the same time we witness the breakdown of communist ideology because of economic and ecological disaster.

There is fear in the Third World that [at present] all the available resources are concentrated to solve the catastrophic heritage of the centrally-planned society and to postpone the solution of the north-south problems to the future [which], I am sure, is not a peaceful solution! The foreign policy of the future must be an environmental foreign policy of international partnership. We need a new kind of disarmament negotiation process - concentrating this time on the fight of Mankind for Nature and environment* — to protect our common future. New weapons are needed in this fight: Debt-for-Nature swaps, technology transfer with new access possibilities, and new additional financial measures. We have to pay for these weapons by using the [expectably huge] peace dividends [namely, what is saved from not arming]!

Even in the short-term we can expect additional effects which will increase considerably in the future:

- there will be a shift in climate zones - for example, of desert areas;

- there will be an increase in large-scale climate-related forest dieback, which may come very quickly because some forests are already suffering [considerable] damage. This must be seen in particular against the backdrop of the fact that, as far as we know today, undamaged vegetation can probably cope with a

* This reminds us of our attempts in recent years to get one of our number granted the Nobel Peace Prize on the basis of Mankind's need for peace being — foreseeably increasingly — with the environment. — Ed. 
temperature increase of $0.1^{\circ} \mathrm{C}$ per decade, whereas the forecasts are that, if emissions continue at present levels, temperatures will increase by $0.3^{\circ} \mathrm{C}$ per decade;

- there will be a deterioration of water resources in many areas; and

- the world food situation has been made considerably worse by climate anomalies (e.g. droughts and floods), crop failures, increased damage to agricultural goods, increased coverage of agricultural lands by buildings and roadways, etc.

The consequences of all this will be starvation, poverty, squalor, and streams of environmental refugees, at a level which we can hardly imagine today.

\section{Objectives and Fields for Action to Counter Environmental Degradation}

In 1987, emissions of $\mathrm{CO}_{2}$ stood at around 20.5 thousand million tons, compared with a level of around 22 thousand millions in 1990. If the trend in present global growth-rates in energy consumption were to continue, energy-related $\mathrm{CO}_{2}$ emissions would about double by the year 2050 . To protect the Earth's atmosphere, however, it will be necessary to decrease $\mathrm{CO}_{2}$ emissions by $50 \%$ by the middle of the next century. This objective also has the additional effect of reducing other energy-related emissions of hazardous substances, and thus other environmental impacts of energy-use such as, for example, forest dieback.

Throughout the world, the protection of the Earth's atmosphere is seen as the greatest environmental challenge which we have yet to face. This is a challenge which can only be met by consistent action. Preventive steps must be taken, with immediate measures at both national and international levels, to put a check on the 'greenhouse' effect. This means:

- phasing out the use and production of CFCs and other ozone-depleting gases, which are also 'greenhouse' substances;

- protecting forests - in particular tropical forests - and taking reafforestation measures in all suitable areas; and

- reducing climate-relevant emissions from the agricultural sector, waste-deposit sites, and other sources; but,

- in particular, it also means reducing energy-related, climate-relevant emissions.

\section{Climate Convention}

In a continuation of the work of IPCC and of the Second World Climate Conference which was held here in Geneva in 1990 [see above], intensive governmental negotiations have been going on since February 1991, under the auspices of the United Nations, on a global climate convention.

In line with the work already done by the Intergovernmental Negotiating Committee (INC), I believe the most promising strategy [would be] a comprehensive climate convention to include all relevant problem areas - such as energy, forest protection, agriculture, and waste.

[Furthermore,] I believe that it is our obligation, in spite of the enormous [pressures we are under in other respects], to put every effort into ensuring that [such a] climate convention and, if possible, initial implementing protocols to reduce climate-relevant [effects - ] in particular energy-related emissions together with measures to protect forests in their function as $\mathrm{CO}_{2}$ storages and sinks - can be signed as early as at the United Nations Conference on Environment and Development (UNCED), to be held in Brazil in June 1992.

\section{Reduction Objectives}

To protect the Earth's atmosphere I believe it is necessary to take the initial step of stabilizing, at 1990 levels, global $\mathrm{CO}_{2}$ emissions by the year 2000 , and subsequently to reduce them considerably in further stages - so that, by the year 2050 , emissions will have dropped to around half their present level.

It is the industrialized countries which bear special responsibility here, as around two-thirds of present emissions come from these countries. By drastically limiting and reducing their emissions of 'greenhouse' gases, the industrialized countries will have to make the decisive contribution to achieving this aim. But the developing countries too - and let me make it clear that I believe that there is no question but that they should continue developing - should also meet their responsibilities in limiting increases in emissions.

Apart from approaching the problem at an international level, every country is called upon to take immediate national measures and to initiate long-term strategies to protect the environment and in particular the Earth's atmosphere. The international approach must not mean that no measures are taken at the national level until the corresponding international agreements have been concluded.

The European Community has a particularly important role to play here. In 1990 the EC decided to stabilize total $\mathrm{CO}_{2}$ emissions within the Community at AD 1990 levels by the year 2000, and subsequently to reduce them.

The Federal Republic of Germany has already taken national decisions which go far beyond EC objectives:

In November 1990, Germany approved a $\mathrm{CO}_{2}$-reduction programme, setting the objective of reducing $\mathrm{CO}_{2}$ emissions by at least $25 \%$ in the original Federal Republic, with more far-reaching reductions in the new Federal Länder, by the year 2005. The Federal Chancellor Dr Helmut Kohl put this objective into more concrete terms in his governmental 
declaration of 30 January 1991, so that the Federal Government is now working towards reducing $\mathrm{CO}_{2}$ emissions by

$25 \%$ to $30 \%$ [from] 1987 levels by the year 2005 for the total area of the Federal Republic as it stands today.

This decision, taken by the Federal Government, ties in with the recommendation of the [above-mentioned Enquiry] Commission on Preventive Action to Protect the Earth's Atmosphere set up by the 11th German Bundestag which, in its third report, in October 1990, called for a 30\% reduction in $\mathrm{CO}_{2}$ emissions by $\mathrm{AD} 2005$ over AD 1987.

Given that, in 1987, [Federal German] $\mathrm{CO}_{2}$-emission-levels were running at around 1050 million tons, this objective means that there will be a reduction of around 300 million tons to around 750 million tons by the year 2005. The first range of measures to implement this ambitious objective was passed by the Federal Government on 7 November 1990 in the form of the $\mathrm{CO}_{2}$ reduction programme.

\section{Priority for Energy Efficiency and Renewable Energies}

Priority in reducing energy-related, climate-relevant emissions, and in particular emissions of $\mathrm{CO}_{2}$, is given both to energy-saving measures and to the extension of the use of renewable energies. The changes necessarily affect both energy suppliers and energy users. Energy, environment, and traffic, legislation in our country, and the measures required to implement the changes, must be appropriate to the circumstances, with a differentiated and multifaceted approach to administrative law, taxes, and pricing policy.

Many people are surprised to hear of the potential for $\mathrm{CO}_{2}$ reduction which already exists today. In the original Länder [provinces] of the Federal Republic of Germany, a study prepared for the Enquiry Commission, on preventive action to protect the Earth's atmosphere by the 11th German Bundestag, showed the following technical potential for $\mathrm{CO}_{2}$ reduction:

-70 to $90 \%$ for existing buildings;

-70 to $80 \%$ for new buildings;

-40 to $70 \%$ for small consumers;

-30 to $70 \%$ for electrical appliances;

-50 to $60 \%$ for cars and aeroplanes;

- 10 to $50 \%$ for water-heating;

-15 to $25 \%$ for buses, lorries, and fuels used in industry, power-stations, and refineries; and

-10 to $15 \%$ for power generation and for electricity used in industry.

In total, then, state-of-the-art technology means that, in the original Federal Länder, there is a 35 to $45 \%$ potential for $\mathrm{CO}_{2}$ reduction merely by taking measures to use energy more rationally [than is currently the practice]. The technical potential is of course not synonymous with the potential which can be tapped by the year 2005; that which is lower because of questions of cost, other conditions, and various obstacles that exist at the moment. It does, however, show us the way forward.

\section{Costs of Climate Protection}

In conclusion, let me [consider] the costs of climate protection. The innovations in restructuring processes [that will be] necessary to reduce hazardous substances, do not only have to be implemented for the protection of the climate and the environment; in economic terms, they offer the most stable perspectives for long-term future development. We know this conclusively, now that we can really see the sheer dimension of the tremendously high damage-potential of threatened climate change and have an inkling of the long-term external costs of today's energy-use.

Investments in efficient technologies and new concepts for energy-saving, the use of renewable energies, and reductions in hazardous substances, which are being introduced [nowadays] are, therefore, from an ecological point of view, a central concern of humanity.

\section{Conclusion}

May I take this opportunity of wishing the World Clean Energy Conference every success, and express my hope that your convincing results will help to build up a world-wide environmentally-compatible energy system.

KLAUS TÖPFER, Minister

Ministry of the Environment, Nature Protection, and Nuclear Safety

Government of Germany

Postfach 120629

D-5300 Bonn 1

Germany. 